The contribution of molecular packing, crystal forces and steric interference between isopropyl groups of neighbouring molecules on the deformation of the $\mathrm{PbS}_{6}$ group is being studied.

We thank J. J. Dickert for supplying the crystals of this material, L. S. Bartell for recognizing the presence and interesting stereochemical influence of the lone pair, and J. J. Wise and C. N. Rowe for helpful discussions.

STEPHEN L. Lawton GEORGE T. KOKOTAILO

Department of Research,

Mobil Research and Development Corporation,

Paulsboro Laboratory,

Paulsboro, New Jersey.

Received September 3; revised December 19, 1968.

1 Sidgwick, N. V., and Powell, H. M., Proc. Roy. Soc., A, 176, 153 (1940).

${ }^{2}$ Gillespie, R. J., and Nyholm, R. S., Quart. Rev., 11, 339 (1957).

${ }^{3}$ Gillespie, R. J., Canad. J. Chem., 38, 818 (1960).

4 Gillespie, R. J., J. Chem. Educ., 40, 295 (1963).

5 Gillespie, R. J., Adv. Chem. Ser., No. 62, 221 (1967)

- Britton, D., Canad. J. Chem., 41, 1632 (1963).

7 Claxton, T. A., and Benson, G. C., Canad. J. Chem., 44, 157 (1966).

${ }^{8}$ Claxton, T. A., and Benson, G. C., Canad. J. Chem., 44, 1730 (1966)

${ }^{2}$ Thompson, H. B., and Bartell, L. S., Inorg. Chem., 7, 488 (1968). ${ }^{10}$ Lord, R. C., Lynch, M. A., Schumb, W. C., and Slowinski, E. F., J. Amer *

${ }^{11}$ Donohue, J., Acta Cryst., 18, 1018 (1965).

${ }^{12}$ Thompson, H. B., and Bartell, L. S., Trans. Amer. Cryst. Assoc., 2, 190 (1966).

${ }^{13}$ Bartell, L. S., Gavin, R. M., Thompson, H. B., and Chernick, C. L., J. Chem. Phys., 43, 2547 (1965).

${ }^{14}$ Hedberg, K., Peterson, S. H., Ryan, R. R., and Weinstock, B., J. Chem Phys., 44, 1726 (1966).

${ }^{10}$ Gavin, R. M., and Bartell, L. S., J. Chem. Phys., 48, 2460 (1968).

${ }^{16}$ Bartell, L. S., and Gavin, R. M., J. Chem. Phys., 48, 2466 (1968).

17 Engel, G., Z. Krist., 90, 341 (1935),

${ }^{8}$ Hoard, J. L., and Dickenson, B. N., Z. Krist., 84, 436 (1933).

${ }^{19}$ Hazell, A. C., Acta Chem. Scand., 20, 165 (1966).

20 Brown, I. D., Canad. J. Chem., 42, 2758 (1964).

${ }^{21}$ Das, A. K., and Brown, I. D., Canad. J. Chem., 44, 939 (1966).

${ }^{22}$ Lawton, S. L., and Jacobson, R. A., Inorg. Chem., 5, 743 (1966).

${ }^{23}$ Urch, D. S., J. Chem. Soc., 5775 (1964).

${ }^{24}$ Dickert, J. J., and Rowe, C. N., J. Org. Chem., 32, 647 (1967)

${ }_{25}$ Wells, A. F., Structural Inorganic Chemistry, 527 (Clarendon Press, Oxford, 1962). ${ }^{26}$ Pauling, L., The Nature of the Chemical Bond, 260 (Cornell Univ. Press,

\section{Hyperfine Structure in the Electron Spin Resonance Spectra of Reduced Chromium and Iron Phthalocyanins}

HYPERFINE structure (h.f.s.) arising from interaction of the unpaired electron with nitrogen or hydrogen atoms of the phthalocyanin $(\mathrm{Pc})$ or porphin ring system in metal complexes has been observed in only a few cases. Copper complexes readily exhibit nitrogen h.f.s., and there is evidence for it in reduced cobalt phthalocyanin tetrasulphonate $^{1}$. Both nitrogen and hydrogen h.f.s. are observed in reduced zinc aetioporphyrin and zinc tetrabenzporphyrin ${ }^{2}$.

When we reduced chromium phthalocyanin by $\mathrm{Na} / \mathrm{THF}$ we obtained a well resolved nine line spectrum with relative intensities $1: 4: 10: 16: 19: 16: 10: 4: 1$, centred on $g=1.975$ and with a spacing of 3.05 gauss. We attributed this to interaction of the unpaired electron with the four inner nitrogen atoms of the phthalocyanin. The signal decreases in intensity without further reduction, and is replaced by a similar spectrum with splitting $3 \cdot 15$ gauss and $g=1.981$. This latter spectrum also shows coupling to ${ }^{53} \mathrm{Cr}(21.6$ gauss $)$. On freezing to $77^{\circ} \mathrm{K}$, a symmetrical line at $g=\mathbf{1 . 9 7 5}$ is seen together with features associated with $A_{\|}\left({ }^{53} \mathrm{Cr}\right)$ (35 gauss). There seem to be two species in solution and we attribute the electron spin resonance (ESR) spectra to a metal ion with configuration $e_{g}\left(d_{x z, y z}\right)^{4}, b_{2 g}\left(d_{x y}\right)^{1}$, the ${ }^{14} \mathrm{~N}$ hyperfine coupling probably resulting from spin polarization of the $\sigma$ electrons.

When we reduced $\mathrm{CrPc}$ with $\mathrm{Na} /$ hexamethylphosphoramide (HMPA), a 17 line spectrum with average spacing 2.04 gauss and centred on $g=2.0029$ was obtained. There was no evidence for ${ }^{53} \mathrm{Cr}$ hyperfine splitting. This spectrum is attributed to an unpaired electron largely localized in a phthalocyanin $\pi$-orbital and interacting roughly equally with all eight nitrogen atoms. The strong $\pi$ interaction between the HMPA and the $\mathrm{CrPc}$ will raise the energy of the $e_{g}$ orbitals so that they are higher than the $b_{2 g}$ orbital. The electron configuration will now be $b_{2 g^{2}}$, $e_{g^{3}}$ with the unpaired electron in the $e_{g}$ orbital which must have considerable ligand character.

When a solution of iron phthalocyanin was reduced by $\mathrm{Na} / \mathrm{THF}$, a well resolved nine line spectrum similar to that for $\mathrm{CrPc}$ was observed. It was centred on $g=2.01$ and had a spacing of 2.4 gauss. On further reduction, the signal disappeared, and was eventually replaced by a single isotropic broad line $(\Delta H=12$ gauss) at $g=2.0030$. When reduction was carried out using Na/HMPA, a poorly resolved nine line spectrum at $g=1.987$ was observed with a spacing of about $2-3$ gauss. These results are consistent with an electron being added initially to the $a_{1 g}\left(d_{z^{2}}\right)$ orbital to give a $d^{7}\left(\mathrm{Fe}^{+}\right)$ion with interaction of the unpaired electron with each of the four inner nitrogen atoms. The $g$ values vary either side of 2 because of the allowed mixing by spin orbit coupling of the $a_{1 g}$ orbital with both the filled $e_{g}$ (which is very dependent on $\pi$ bonding to the solvent HMPA), and empty $e_{g}(\pi)$ ligand orbitals. A second electron yields the diamagnetic $d^{8}\left(\mathbf{F e}^{0}\right)$ species and a third can then be added to the lowest empty $\pi$ orbital on the phthalocyanin.

\section{M. GuzY}

J. B. RAYNOR

L. P. STODULSkI

Department of Chemistry,

University of Leicester.

Received October 30, 1968.

${ }^{1}$ Rollman, L. D., and Iwamoto, R. T., J. Amer. Chem. Soc., 90, 1455 (1968). ${ }^{2}$ Hush, N. S., and Rowlands, J. R., J. Amer. Chem. Soc., 89, 2976 (1967).

\section{Nitrogen Complexes as Models for Nitrogenase with Nitrogen on the Active Site}

NITROGEN gas reacts in mild conditions in protic media to give the nitrogen complexes $\left[\mathrm{CoH}\left(\mathrm{N}_{2}\right)\left(\mathrm{PPh}_{3}\right)_{3}\right]^{1}$, and $\left[\mathrm{Ru}\left(\mathrm{NH}_{3}\right)_{5}\left(\mathrm{~N}_{2}\right)\right] X_{2}(X=\text { mono anion })^{2}$, and related complexes, but the complexed nitrogen molecule has not yet been reduced to ammonia ${ }^{3}$. Nevertheless, the mechanism of nitrogen uptake in the formation of these complexes may represent the process by which nitrogen is bound in nitrogenase, and the reduction to ammonia could occur in nature by protonation of the complexed nitrogen with simultaneous influx of electrons from the metal. We have therefore studied quantitatively the reactions with strong acids of $\left[\mathrm{CoH}\left(\mathrm{N}_{2}\right)\left(\mathrm{PPh}_{3}\right)_{3}\right]^{1}$, the substance formulated as $\left[\mathrm{Co}\left(\mathrm{N}_{2}\right)\left(\mathrm{PPh}_{3}\right)_{3}\right]^{4}$, trans $-\left[\operatorname{IrCl}\left(\mathrm{N}_{2}\right)\left(\mathrm{PPh}_{3}\right)_{2}\right]^{5}$, and $\left[\mathrm{Ru}\left(\mathrm{NH}_{3}\right)_{5}-\right.$ $\left.\left(\mathrm{N}_{2}\right)\right] X_{2}\left(X=\mathrm{Cl} \text { or } \mathrm{BF}_{4}\right)^{6, ?}$. If protonation occurred, some reduction of the nitrogen with simultaneous oxidation of the metal would be expected. We have found that in general there is oxidation of the metal by the acid, but it leads to nitrogen evolution, often together with hydrogen, and no ammonia.

The nitrogen complexes were prepared as described in refs. 1-6, except that $\left[\mathrm{Co}\left(\mathrm{N}_{2}\right)\left(\mathrm{PPh}_{3}\right)_{3}\right]$ was better obtained using $\mathrm{AlEt}_{3}$ in ether, instead of $\mathrm{AlEt}_{2}(\mathrm{OEt})$. Nevertheless, this cobalt complex was never obtained pure, and our best material contained about 15 per cent $\left[\mathrm{CoH}\left(\mathrm{N}_{2}\right)\right.$ $\left.\left(\mathrm{PPh}_{3}\right)_{3}\right]$ (determined by reaction with $\mathrm{DCl}$ ) which we 